\title{
Micro e macrominerais séricos em suínos, fêmeas e machos castrados, em idade de abate
}

\section{Seric micro and macromineral in female and castrated male slaughter}

\author{
Celso José Bruno de Oliveira, ${ }^{\star}$ Luiz Fernando de Oliveira e Silva Carvalho, ${ }^{\star \star}$ Áureo Evangelista Santana**
}

\begin{abstract}
Resumo
O presente estudo objetivou quantificar os níveis séricos de micro e macrominerais de suínos fêmeas e machos castrados, em idade de abate e criados em sistema intensivo, visando estabelecer os valores de referência correspondentes. Foram empregados 195 animais e as análises realizadas por espectrofotometria de absorção atômica e por kits comerciais. Os valores médios obtidos foram: Ca: $12,35 \pm 2,87 \mathrm{mg} / \mathrm{dL} ; \mathrm{P}: 7,27 \pm 2,05 \mathrm{mg} / \mathrm{dL} ; \mathrm{K}: 6,14 \pm 1,14 \mathrm{mmol} / \mathrm{L} ; \mathrm{Na}: 148,5 \pm 38,53 \mathrm{mmol} /$ $\mathrm{L} ; \mathrm{Mg} 2,37 \pm 0,62 \mathrm{mg} / \mathrm{dL} ; \mathrm{Fe}: 2,36 \pm 1,10 \mu \mathrm{g} / \mathrm{mL}$; Cu: $3,91 \pm 1,52 \mu \mathrm{g} / \mathrm{mL}$ e $\mathrm{Zn}: 1,92 \pm 0,928 \mu \mathrm{g} / \mathrm{mL}$. Os resultados näo permitiram o estabelecimento dos valores de referência correspondentes aos macro e microminerais estudados, como era o desejado.
\end{abstract}

Palavras-chave: minerais, suínos, bioquímica clínica, cálcio, fósforo, sódio, magnésio, potássio, cobre, ferro, zinco.

\begin{abstract}
Regarding the few information on seric mineral levels in pigs and the number of different factors that may affect them, this study focused on the establishment of the reference values of seric calcium, phosphate, sodium, magnesium, potassium, copper, iron and zinc in female and castrated male market pigs raised intensively. Blood samples of 195 pigs, were collected and after blood coagulation, serum was separated for the laboratorial analysis. Determinations of serum concentrations of calcium, sodium, potassium, iron, copper and zinc were performed by atomic absorption spectrophotometry and determination of phosphate and magnesium serum levels, were conducted by using commercial proper kits. Serum levels for calcium, phosphate, potassium, sodium, magnesium, iron, copper and zinc were, respectively, $12,35 \mathrm{mg} / \mathrm{dL}, 7,27 \mathrm{mg} / \mathrm{dL}, 6,14 \mathrm{mmol} / \mathrm{L}, 148,5 \mathrm{mmol} /$ $\mathrm{L}, 2,37 \mathrm{mg} / \mathrm{dL}, 2,36 \mu \mathrm{g} / \mathrm{mL}, 3,91 \mu \mathrm{g} / \mathrm{mL}$ and $1,92 \mu \mathrm{g} / \mathrm{mL}$. Results showed a significant difference among castrated male and female mineral serum concentrations. Serum concentrations of potassium, sodium, calcium, copper and zinc were higher in females than in males and serum levels of phosphate were higher in castrated males. Regarding the disagreement among the data of this study and those mentioned in the literature, each laboratory must establish its own seric mineral reference values.
\end{abstract} Keywords: mineral, swine, clinical chemistry, calcium, phosphate, magnesium, potassium, copper, iron, zinc, sodium, reference
values.

\section{Introdução}

As concentrações séricas de minerais têm sido determinadas com a finalidade de auxiliar nas investigações do metabolismo e na determinação de requerimentos nutricionais dos suínos. Adicionalmente, representam um meio de mensurar efeitos subclínicos em estudos envolvendo toxicologia e farmacologia (Friendship e Henry, 1992). A bioquímica clínica oferece, ainda, importantes perspectivas quando utilizada em programas de monitoramento da saúde de rebanhos suínos pois, apesar dos minerais constituírem quantidade relativamente pequena do total dos componentes do organismo, alterações em seus niveis séricos podem indicar deficiências/excessos nutricionais ou processos patológicos em seus estágios precoces.
De acordo com Odink et al. (1990), o aumento nas concentrações séricas de ferro, fosfato e magnésio está relacionado a processos inflamatórios, como pleurites, pneumonias e abscessos. Existe, ainda, a possibilidade de utilização dos parâmetros séricos de alta herdabilidade na seleção. indireta de reprodutores para certas características desejáveis. Estudos demonstram que os niveis séricos de alguns parâmetros apresentam alta relação com características ligadas à resistência a doenças, qualidade da carne e capacidade produtiva (Lingaas et al., 1992b). Além disso, a crescente utilização do suíno como modelo experimental nas pesquisas em medicina humana reflete a importância da bioquímica clínica nessa espécie (Tumbleson e Schmidt, 1986).

Os avanços científicos na área de bioquímica clínica e sua potencial utilização na produção de suínos não condizem com

\footnotetext{
* Departamento de Patologia Animal da Faculdade de Ciências Agrárias e Veterinárias-Unesp campus de Jaboticabal, Brasil. Endereço: Via de acesso Rodovia Paulo Castellane s/n, Km 5 s/n CEP 14870-000. E-mail: celsojbo@fcav.unesp.br * Departamento de Clinica e Cirurgia Veterinária - Faculdade de Ciências Agrárias e Veterinárias-Unesp campus de Jaboticabal, Brasil. Endereço:
Via de acesso Rodovia Paulo Castellane s/n CEP 14870-000. E-mail: Ifosc@fcav.unesp.br
} 
a escassez de dados referentes aos valores de normalidade dos principais parâmetros séricos nesta espécie. Apesar da existência de dados genéricos sobre valores normais de alguns parâmetros séricos em suínos (Blood et al., 1979; Kaneko 1989; Doherty e Mulville, 1992; Gresham, 1994; Meyer et al., 1995), sabe-se que os mesmos podem sofrer influência direta de fatores como idade, sexo, estação climática, estado fisiológico, perfil racial e sistema de criação (Tumbleson e Schmidt, 1986; Egeli et al., 1998). Ocorrem, inclusive, divergências entre estudos sobre valores séricos normais em suínos em idade de abate (Uilrey et al. 1967; Dorner et al., 1983; Friendship et al. 1984; Odink et al., 1990). O objetivo do presente estudo foi determinar os niveis séricos de macro e microminerais (cálcio, potássio, fósforo, sódio, magnésio, ferro, cobre e zinco) em suínos sadios, fêmeas ou machos castrados, criados em sistemas intensivos de produção.

\section{Material e métodos}

Foram utilizados 195 suínos three cross, sendo 94 machos castrados e 101 fêmeas, com idade de 140-150 dias. As amostras foram coIhidas durante o momento da sangria, por ocasião do abate, em frigorífico localizado na região de Ribeirão Preto-SP. A determinação das concentrações séricas de cálcio, sódio, potássio, ferro, cobre e zinco foram realizadas por espectrofotometria de absorção apropriados $^{\text {b }}$ para as determina . Utilizaram-se, ainda, kits fósforo e magné as determinações dos níveis séricos de fósforo e magnésio, realizados respectivamente pelos métomeiro, os ions fosfato reagem L L Mann e Yoe. No priácido, formando um reagem com o molibdênio em meio tampã alcalino é reduzido a comarelo que, por ação de um colorimetricamente (Santos, a azul molibdênico, que é medido colorimétricamente (Santos, 1999). O corante de Mann e Yoe, em $\mathrm{pH}$ alcalino, e em presença de magnésio, desenvolve

\footnotetext{
Espectrofotômetro GBC 932-AA

' LABTEST, Belo Horizonte, MG.
}

Tabela 1. Valores mínimos, máximos e médios de micro e macrominerais séricos de suínos

\begin{tabular}{|c|c|c|c|c|c|c|c|}
\hline Parâmetros & Unidade & Média & $\begin{array}{c}\text { Mínimo } \\
\text { Observado }\end{array}$ & $\begin{array}{l}\text { Máximo } \\
\text { Observado }\end{array}$ & $\begin{array}{l}\text { Desvio - } \\
\text { Padrão }\end{array}$ & CV (\%) & $\begin{array}{c}\text { Teste } \\
\text { K-S } \\
\text { p }\end{array}$ \\
\hline Cálcio & $\mathrm{mg} / \mathrm{dL}$ & 12,35 & 4,95 & 21,3 & 2,87 & 13,71 & $>0,15$ \\
\hline Fósforo & $\mathrm{mg} / \mathrm{dL}$ & 7,27 & 2,53 & 17,9 & 2,05 & 19,69 & $>0,15$ \\
\hline Potássio & $\mathrm{mmol} / \mathrm{L}$ & 6,14 & 2,834 & 8,80 & 1,14 & 17,39 & $>0,15$ \\
\hline Sódio & $\mathrm{mmol} / \mathrm{L}$ & 148,5 & 60,94 & 272,14 & 38,53 & 4,18 & $<0,01$ \\
\hline Magnésio & $\mathrm{mg} / \mathrm{dL}$ & 2,37 & 1,1 & 4,4 & 0,62 & 33,2 & $<0,01$ \\
\hline Cobre & $\mu \mathrm{g} / \mathrm{mL}$ & 3,91 & 1 & 11,5 & 1,52 & 44,4 & $<0,01$ \\
\hline Ferro & $\mu \mathrm{g} / \mathrm{mL}$ & 2,36 & 0,25 & 6,75 & 1,10 & 31,5 & $<0,01$ \\
\hline Zinco & $\mu \mathrm{g} / \mathrm{mL}$ & 1,868 & 0,5 & 8,25 & 0,928 & 51,7 & $<0,01$ \\
\hline
\end{tabular}

de confiança, que o referido parâmetro não nivel de $95 \%$ de probabilidade, ou seja, pode-se afirmar, com $95 \%$ teste foi significativo ao nivel de $99 \%$ de probabilidade $p>0,05$ indica nol na população. $p<0,01$ indica que 0 de $95 \%$ de probabilidade, ou seja, os valores possuem distribuição que o teste não foi significativo ao nivel significativo ao nivel de $85 \%$ de probabilidade.

Tabela 2. Valores mínimos, máximos e médios de micro e macrominerais séricos de suínos, 

\begin{tabular}{|c|c|c|c|c|c|c|c|c|}
\hline & Parâmetros & Unidade & Média & $\begin{array}{c}\text { Minimo } \\
\text { Observado }\end{array}$ & $\begin{array}{c}\text { Máximo } \\
\text { Observado }\end{array}$ & $\begin{array}{l}\text { Desvio - } \\
\text { Padräo }\end{array}$ & CV $(\%)$ & $\begin{array}{c}\text { Teste } \\
\text { K-S } \\
\text { p }\end{array}$ \\
\hline \multirow{8}{*}{$\begin{array}{l}\text { M } \\
\mathbf{a} \\
\mathbf{C} \\
\mathbf{h} \\
\mathbf{0} \\
\mathbf{S}\end{array}$} & Cálcio & $\mathrm{mg} / \mathrm{dL}$ & 11,12 & 4,95 & 19,4 & 2,75 & 14,80 & $>0,15$ \\
\hline & Fósforo & $\mathrm{mg} / \mathrm{dL}$ & 7,648 & 3,47 & 11,2 & 1,49 & 15,90 & $>0,15$ \\
\hline & Potássio & $\mathrm{mmol} / \mathrm{L}$ & 5,652 & 2,834 & 8,307 & 1,10 & 18,55 & $>0,15$ \\
\hline & Sódio & $\mathrm{mmol} / \mathrm{L}$ & 135,3 & 60,94 & 268,18 & 36,78 & 4,48 & $<0,01$ \\
\hline & Magnésio & $\mathrm{mg} / \mathrm{dL}$ & 2,391 & 1,1 & 4,2 & 0,633 & 33,19 & $<0,01$ \\
\hline & Ferro & $\mu \mathrm{g} / \mathrm{mL}$ & 2,430 & 0,5 & 6,75 & 1,00 & 41,10 & $<0,01$ \\
\hline & Cobre & $\mu \mathrm{g} / \mathrm{mL}$ & 3,56 & 1 & 6,5 & 1,31 & 32.15 & $<0,01$ \\
\hline & Zinco & $\mu \mathrm{g} / \mathrm{mL}$ & 1,635 & 0,5 & 3,25 & 0,528 & 44.40 & $<0,01$ \\
\hline & Cálcio & $\mathrm{mg} / \mathrm{dL}$ & 13,48 & 6,95 & 21,3 & 2,478 & 11,65 & $>0,15$ \\
\hline$F$ & Fósforo & $\mathrm{mg} / \mathrm{dL}$ & 6,916 & 2,53 & 17,9 & 2,42 & 22,49 & $>0,15$ \\
\hline$\hat{\mathbf{e}}$ & Potássio & $\mathrm{mmol} / \mathrm{L}$ & 6.601 & 4,082 & 8,801 & 0,973 & 14,94 & $>0,15$ \\
\hline m & Sódio & $\mathrm{mmol} / \mathrm{L}$ & 160,8 & 86,9 & 272,14 & 36,1 & 3.73 & $<0,01$ \\
\hline e & Magnésio & $\mathrm{mg} / \mathrm{dL}$ & 2,351 & 1,12 & 4,4 & 0,612 & 33,27 & $<0,05$ \\
\hline $\mathbf{a}$ & Ferro & $\mu \mathrm{g} / \mathrm{mL}$ & 2,300 & 0,25 & 5,25 & 1,178 & 4.70 & $<0.05$ \\
\hline s & Cobre & $\mu \mathrm{g} / \mathrm{mL}$ & 4,240 & 1,25 & 11,5 & 1,624 & 30,35 & $<0,01$ \\
\hline & ZZinco & $\mu \mathrm{g} / \mathrm{mL}$ & 2,088 & 0,75 & 8,25 & 1,147 & 51,29 & $<0,01$ \\
\hline
\end{tabular}

de confiança, que o referido parâmetro nāo apresenta uma distribuicão, ou seja, pode-se afirmar, com $95 \%$ que o teste foi significativo ao nível $99 \%$ de probabilidade $p>0,05$ inção normal na população. $p<0,01$ indica nivel de $95 \%$ de probabilidade, ou seja, o parâmetro possui distribuição que o teste não foi significativo ao foi significativo ao nível de $85 \%$ de probabilidade.

coloração vermelha. A intensidade de cor vermelha do com plexo é proporcional à concentração do magnésio, podendo por isso ser utilizada na sua determinação (Santos, 1999). Para a avaliação da distribuição dos valores, foi utilizado o teste de normalidade Kolmogorov-Smirnov (KS) ${ }^{c}$. O estabelecimento dos valores de referência mínimos e máximos fo realizado segundo o método dos Percentis (Farver, 1989) adotando-se como limites, mínimo e máximo, os valores referentes aos percentis 2,5 e 97,5. O efeito do sexo sobre cada parâmetro sérico foi avaliado segundo teste t para variáveis independentes ${ }^{c}$ quando o parâmetro em questão apresentou ado pelo teste não-paramétricário, o efeito do sexo foi avali-

" SAS Institute, Inc., Cary, NC. 


\section{Resultados e discussão}

Os parâmetros, cálcio, fósforo, potássio e sódio apresentaram distribuição normal na população, quando os resultados foram avaliados pelo teste K-S, ao contrário do magnésio $(p<0,01)$, cobre $(p<0,01)$, ferro $(p<0,01)$ e zinco $(p<0,01)(T a-$ bela 1). Quando o fator sexo foi considerado, conforme a Tabela 2, magnésio $(p<0,05)$, cobre $(p<0,01)$, ferro $(p<0,05)$, zinco $(p<0,01)$ e sódio $(p<0,01)$ não apresentaram distribuição normal.

Os resultados obtidos demonstraram que alguns parâmetros não apresentaram distribuição normal. Apesar de muitas vezes desconsiderado, o teste de normalidade é fundamental no processo de elaboração dos valores de referência para minerais, pois existe uma gama de variáveis biológicas que não assumem distribuição normal. Em conseqüência, foi adotado o Método dos Percentis para a determinação dos valores de referência, máximos e mínimos, uma vez que o mesmo pode ser aplicado a variáveis que possuem ou não distribuição normal na população (Farver, 1989) (Tabela 3).

Tabela 3: Valores séricos de micro e macrominerais em suínos, machos castrados e fêmeas, em idade de abate.

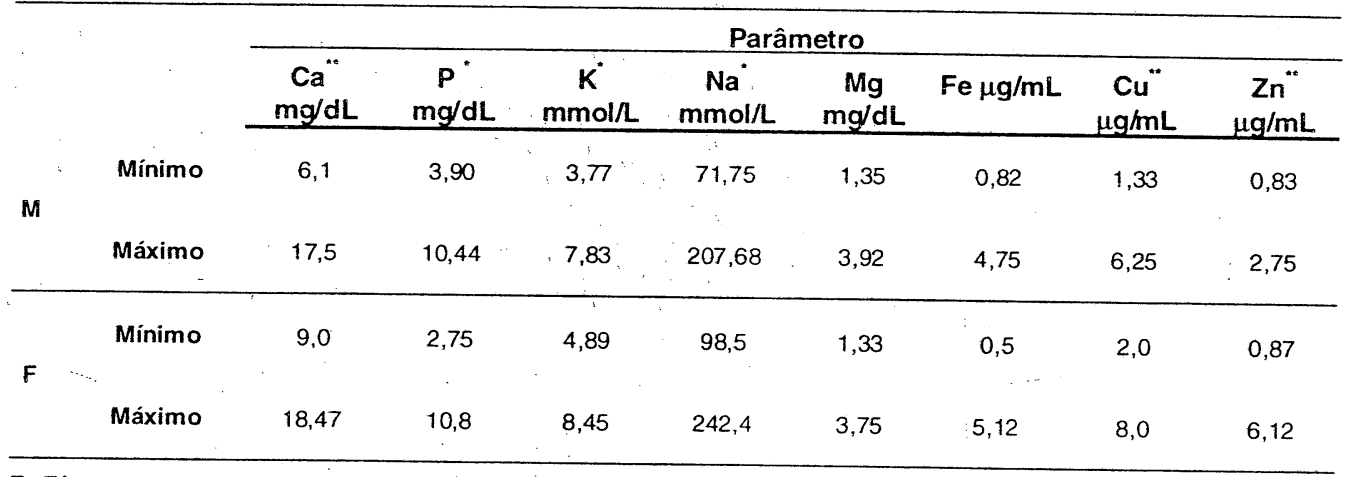

F: Fêmeas; M: Machos castrados;

* Ocorre, para o parâmetro em questāo, efeito significativo do sexo ao nivel de $95 \%$ de probabilidade $(p<0,05)$; ** Ocorre, para o parâmetro em questão, efeito significativo do sexo ao nivel de $99 \%$ de probabilidade
$(p<0,01)$.

Diversos estudos foram realizados relativamente às concentrações séricas de minerais em suínos em idade de abate (Ullrey et al., 1967; Friendship et al., 1984; Odink et al., 1990; Dorner et al.,1983). Os niveis dos minerais sódio, cobre, ferro e zinco, obtidos pelo presente estudo, apresentaram maior amplitude em seus intervalos de normalidade, quando comparados aos resultados de outros estudos (Tabela 4). O mesmo ocorreu para o cálcio e o fósforo, porém, de maneira menos acentuada. Essas diferenças mostram que conclusões equivocadas podem ser tomadas, em relação aos níveis séricos de cobre, ferro, sódio, cálcio e fósforo, dependendo dos valores de referência utilizados. Os valores séricos de potássio e magnésio encontrados no presente estudo são, relativamente, bastante similares aos citados na literatura. Apesar de existirem poucas citações a respeito dos niveis séricos normais de zinco na espécie suína (Hoekstra et al.
1956; Ulirey et al. 1967), os resultados são bastante discrepantes entre si. Isto ocorre, presumivelmente, em decorrência dos niveis nutricionais de zinco influenciarem, de maneira acentuada, a sua concentração sérica (Hoekstra et al., 1956).

Algumas publicações adotam valores de referência genéricos (Blood et al., 1979; Kaneko,1989; Gresham, 1994; Meyer et al., 1995), não sendo citados a idade dos animais ou a fase de criação, gerando variações consideráveis na interpretação dos resultados. Conforme pode ser visto na Tabela 4, os níveis normais de ferro apresentados por estudos em que foram utilizados animais de 140-150 dias de idade (Friendship et al., 1994; Odink et al., 1990) são condizentes entre si e mais elevados do que os valores fornecidos por estudos genéricos.

Com relação ao efeito do sexo, observou-se não haver diferenças nas concentrações séricas de ferro e de magnésio, entre os dois grupos estudados. No entanto, ocorreram niveis séricos significativamente mais elevados de potássio $(p<0,01)$, sódio $(p<0,01)$, cálcio $(p<0,01)$, cobre $(p<0,01)$ e zinco $(p<0,01)$ nas fêmeas, sendo que para o fósforo, encontrou-se concentração mais elevada $(p<0,05)$ no soro dos machos castrados. Esses resultados sugerem a necessidade de elaboração de valores de normalidade para ambos os sexos, como pode ser visto na Tabela 3. Ao contrário, Lingaas et al. (1992b) encontraram niveis significativamente $(p<0,05)$ mais elevados de magnésio nos machos castrados em relação às fêmeas, resultados opostos àqueles apresentados por Odink et al. (1990), o que mostra que a questão ainda merece maiores esclarecimentos.

Há indicações de que os parâmetros séricos sofram influência multifatorial. As divergências entre os resultados apresentados por vários autores são, presumivelmente, resultados da influência desses vários fatores, principalmente relacionados a idade, sexo e sistema de criação ao qual os animais estavam submetidos. Lingaas et al. (1992b) mostraram haver influência significativa da raça sobre vários parâmetros séricos. Foi demonstrado, inclusive, influencia marcante da prática de colheita sobre os valores dos parâmetros mensurados (Dubreuil et al., 1990). Essas divergências podem levar, ainda, a conclusões equivocadas dependendo dos valores que são tomados como normais, evidenciando, portanto, a necessidade de se considerar tais fatores e elaborar valores de referência mais fidedignos. Devese objetivar a padronização das técnicas de colheita e processamento de amostras e, preferencialmente, que cada laboratório construa os seus valores de referência. 
Tabela 4: Comparação entre os valores de referência fornecidos pela literatura relativos aos parâmetros séricos em suínos.

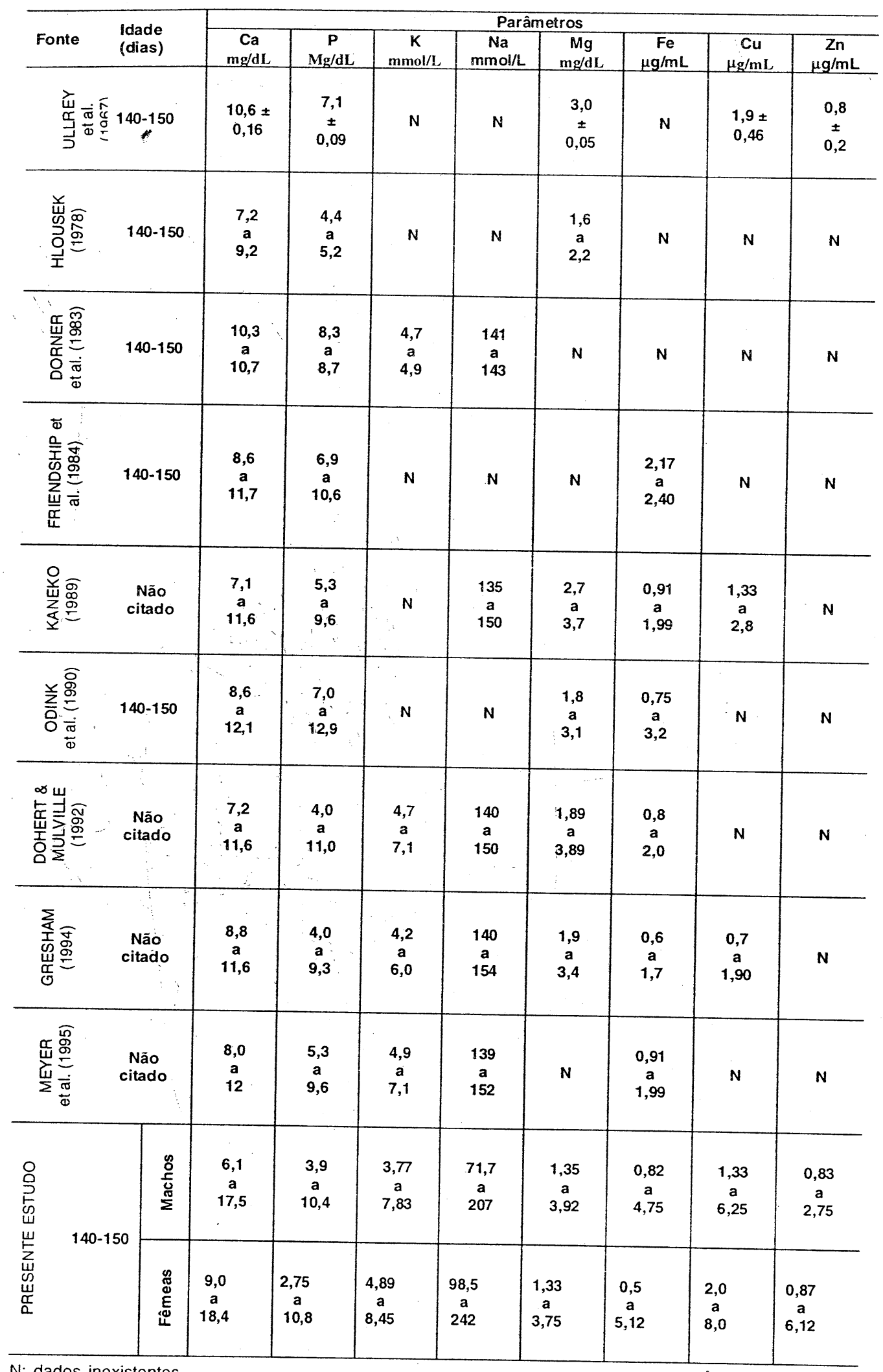

$\mathrm{N}$ : dados inexistentes. 


\section{Referências}

BLOOD, D.C., HENDERSON, J.A., RADOSTITS, O.M. (Ed.) Clínica Veterinária. 5. ed. Rio de Janeiro: Editora Guanabara Koogan, 1979.

DOHERTY, T.J., MULVILLE, J.P. (Ed.) Diagnosis and Treatment of Large Animal Diseases. Philadelphia: W.B. Saunders Company, 1992.

DORNER, J.L., HOFFMANN, W.E., FILIPOV, M.M. Effect of in vitro hemolysis on values for certain porcine serum constituents. Vet. Clin. Pathol., v. 120, p. 15-19, 1983.

DUBREUIL, P, COUTURE, Y., TREMBLAY, A., MARTINEAU, G.P. Effects of experimenters and different blood sampling procedures on blood metabolite values in growing pigs. Can J Vet Res., v. 54, p. 379-382, 1990.

EGELI, A. K., FRAMSTAD, T., MORBERG, $\mathrm{H}$, Clinical biochemistry, haematology and body weight in piglets. Acta Vet. Scand., v. 39, p.
$381-93,1998$.

FARVER, T.B. Concepts of nomality in clinical biochemistry in: KANEKO, J.J. Clinical Biochemistry of Domestic Animals. 4. ed. San Diego: Academic Press, 1989. p.1-20.

FRIENDSHIP, R. M., LUMSDEN, J. H., MCMILILLAN, I., WILSON, M. R. Hematology and biochemistry reference values for Ontario swine. Can. J. Comp. Med., v. 48, p. 390-3, 1984.

FRIENDSHIP, R.M., HENRY, S.C. Cardiovascular system, hematology, and clinical chemistry. In: LEMAN, A. D., STRAW, A. B., MENGELING, W. L., D'LAIRE, S, TAYLOR, D. J. (Ed.) Diseases of Swine. 7. ed. Ames: lowa State University Press, 1992. p. 3-11.

GRESHAM, A.C.J. Porcine clinical biochemistry. Pig Journal, v. 32, p. 58-67, 1994.

HLOUSEK, A. Age-dependent changes in biochemical composition of blood in gilts from large-scale piggeries. Acta VetBmo, v. 47, p. 15-21, 1978.
HOEKSTRA, W. G., LEWIS Jr. P.K., PHILIPS, P.H., GRUMMER, R. H. The relationship of parakeratosis, supplemental calcium and zinc to the zinc content of certain body components of swine. J. Anim. Sci., v. 15, p. 752-64, 1956.

KANEKO, J.J. (Ed.) Clinical Biochemistry of Domestic Animals. 4. ed. San Diego: Academic Press, 1989.

LINGAAS, F., BRUN, E., AARSKAUG, T., HAVRE, G. Biochemical blood parameters in pigs. 2. Estimates of heritability for 20 blood parameters. J. Anim. Breed. Genet, v. 109, p. 281-290, 1992a.

LINGAAS, F., HAVRE, G., FROSLIE, A. AARSKAUG, T. VANGEN, O. Biochemical blood parameters in pigs. 1. Repeatability and effects of breed, litter number and sampling time. J. Anim. Breed. Genet., v. 109, p. 221-230, 1992b.

MEYER, D.J., COLES, JE.H., RICH, L.J. (Ed.) Medicina de laboratório veterinária. 2. ed. São Paulo: Editora Roca, 1995.

ODINK, J., SMEETS, J.F.M., VISSER, I.J.R., SANDMAN, H., SNIJDERS, J.M.A. Hematological and clinicochemical profiles of healthy swirie and swine with inflammatory processes. J. Anim. Sci., v. 68, p. 16370, 1990.

SANTOS, L.C. (Ed.) Laboratório ambiental. Cascavel: Editora e Gráfica Universitária-UNIOESTE, 1999.

TUMBLESON, M.E., SCHMIDT, D.A. (Ed.) Swine clinical chemistry. In: Swine in Biomedical Research. New York: Plenum Press, 1986. p. 783-807.

ULLREY, D.E., MILLER, E.R., BRENT, B.E., BRADLEY, B.L., HOEFER, J.A. Swine hematology from birth to maturity IV. Serum calcium, magnesium, sodium, potassium, copper, zinc and inorganic phosphorus. J. Anim. Sci., v. 26, p. 1024-1029, 1967. 